\title{
Differed Self within Collectivist Culture: Introducing an Alternative Self-Construal Theory
}

\author{
Min $\mathrm{Han}^{1}$, Hye Jin $\mathrm{Kim}^{2, *}$ \& Inumiya Yoshiyuki ${ }^{3}$ \\ ${ }^{1}$ Woosong University, Daejeon, Korea \\ ${ }^{2}$ BARO Research, Seoul, Korea \\ ${ }^{3}$ Seojeong College, Gyeonggi-do, Korea \\ *Correspondence: BARO Research, 211 Hwarang-ro, Seonguk-gu, Seoul, Korea. Tel: 82-2-942-0813. E-mail: \\ esukain@hotmail.com
}

Received: January 19, 2016 Accepted: January 27, 2016 Online Published: January 31, 2016

doi:10.5430/sass.v3n1p37 URL: http://dx.doi.org/10.5430/sass.v3n1p37

\begin{abstract}
Markus and Kitayama's theory of independent and interdependent self has been a powerful framework that unravels the relations between culture and human behavior. However, its dichotomous approach has faced some theoretical limitations in explaining the differences among the countries within the same culture. We suggest an alternative theory with new types of self-construal: subjective self, objective self, and autonomous self. In the present article, the characteristics of the three self-construal types and the measurement scales are introduced as well as the results from the comparative study conducted in Korea, Japan, and China. Moreover, the developmental processes that could cause the disparities in self-construal among these nations are discussed.
\end{abstract}

Keywords: cultures; self-construal; subjective self; objective self; autonomous self

\section{Introduction}

Since the introduction of the concept of individualistic versus collectivistic cultures (Triandis, 1988), the classification of individualism versus collectivism has been employed to explain the disparity between Western and East Asian cultures (Markus \& Kitayama, 1991a). Numerous nations are classified as collectivist cultures, and East Asian nations including Korea, China and Japan are considered as ones of the most typical collectivist countries. However, the people of these nations are profoundly different and geopolitical perspective is necessary to understand the nature of the disparities because culture is the maintenance system of life that people develop in order to adapt to the given environment.

Korea is a peninsula; China is a great part of a continent; and Japan is consisted of islands. Such geological disparity may have been affecting the cognitive and behavioral styles of the people in these three countries. As the tactically critical location, peninsulas always have been the bridgeheads between the continental and maritime forces. The nations in peninsulas have experienced numerous wars and consequently they put extensive efforts to preserve their identities. Located in a peninsula surrounded by China, Mongolia, Russia, and Japan, Korea has been through countless numbers of foreign intrusions and yet the unified dynasties had managed to cultivate their rich and deep histories. Such history requires a significantly strong bond within the society. This bond may be beyond the typical bond generally required in agriculture-oriented collectivistic societies.

On the other hand, the distinctive feature of a continental society is the vastness of the land. China also has a rich history of unified dynasties in such a vast area. Because of the sheer enormousness of the land, numerous dynasties continuously rose and fell within 200 to 300 years. This is different from the dynasties in Korea, which lasted about 500 years. The dynasties of China could not provide proper administrations to all areas in the nation, and this was especially so in the transitional periods between dynasties or historically chaotic eras. Because the administrative power did not reach every corner of the nation, people must have acquired a substantial degree of utilitarianism to survive on their own, hence their strong individualistic tendency. 
Because island is an isolated environment, Japan has rarely experienced foreign intrusions. For a long time, the administrative system of Japan has been consisted of Tenno (the royal king) being the symbolic chief and Bakufu (Shogunate; government of a general) wielding the actual political power. Even though Japan had lowered the barriers and westernized the government systems due to foreign pressures, the fundamental nature had not changed. On the other hand, Korea and China had experienced extreme changes. In both countries, the previous systems that lasted for hundreds of years had collapsed. Moreover, both Korea and China had withstood the foreign invasions and civil wars. Can the people with such history of radical changes and chaotic eras be considered as the same as the people with a relatively stable history?

The classification of collectivistic culture seems too simple and limited. Although East Asian nations share common features such as agriculture-oriented life and Confucianism (Nisbett et al., 2001), the disparities among these cultures are just as great. Until recently, the disparity within the collectivist nations received little attention because the main focus was the similarity and commonness within the same culture. Korea, China, and Japan have distinctively different environment, history, and culture. Thus it is highly probable that such differences may have influenced cognition, emotion, and behavior of the people in each country. Focusing on self-construal, the current research proposes the theory that could explain the psychological disparities among the people of the three East Asian nations.

\subsection{Current Theory of Culture and Self}

Self is a substantially important subject in the field of psychology. Self is the actual being in one's mind and has a profound and critical influence on one's personality, emotion, behavior, and will (Danziger, 1997). Self is discovered through rational implantation of the self, logically systemized and structured (Harre \& Gillett, 1994), and implemented as the criterion of reference in one's everyday life.

Self-construal refers to the awareness of the components comprising the self. Self-concept is the way one realizes one's self. Separated from social context, self-concept is researched mainly in terms of personal psychological adjustment, whereas self-construal is the realization of one's self, structured in social context. Apprehension of self-construal is crucial because the manner and quality of the interaction with others depends on how one perceives the self in social context. Moreover, self-construal regulates personal experiences in social interactions and interpersonal relations, and further determines the characteristics of the culture, to which one belongs.

For many years, cultural self-construal has been treated with great concern in cross-cultural psychology. Especially, Markus and Kitayama (1991a)'s theory of independent self and interdependent self has been applied to the studies that focused on the differences between individualistic and collectivistic cultures. This theory was based on the categorization of individualism and collectivism proposed by Triandis (1988). By adopting Triandis' assumptions about cultures, Markus and Kitayama developed their theory to explain the relation between culture and human behaviors. According to them, a person from individualistic culture develops independent self, and a person from collectivistic culture develops interdependent self. Almost every cross-cultural study have adopted this theory to explain the differences between Eastern countries such as Korea, Japan, and China and Western countries such as the United States and Canada.

Another stream of research comparing Eastern and Western people comes from studies on self-esteem. Self-esteem is defined as one's evaluation on whom and what he/she has, as well as positive and negative feelings toward this evaluation (Rosenberg, 1965). Because self-esteem develops on the basis of cultural values, the level of self-esteem is expected to differ depending on cultures (Markus \& Kitayama, 1991a; Heine \& Lehman, 1995). For example, individualistic cultures encourage people to fulfill self-related values such as self-respect, self-reliance, self-assertion, and self-realization, and require them to be autonomous subjects (Hsu, 1981). On the other hand, in Eastern cultures, one's self is not only believed to be subordinate to the in-group but also is expected to acquire various roles in accordance with the evaluations of the group (Devos, 1973).

Studies indeed have shown that individualistic cultures tend to show higher level of self-esteem than collectivistic cultures (Kwan, Rond, \& Singelis, 1997; Baumeister, Tice, \& Hutton, 1989). In a cross-cultural study, even the individuals who were classified in the low self-esteem group had higher scores than the theoretical criterion, whereas the scores of Japanese participants whom were considered to belong to a collectivistic culture were normally distributed around the theoretical middle point (Heine, Kitayama, Lehman, Takata, Ide, Leung, \& Matsumoto, 2001). However, a different pattern of results on self-esteem was reported in a study conducted with Korean participants. They $(M=5.27, S D=.97)$ had higher self-esteem scores than Japanese $(M=4.29, S D=.98)$ (Cho, Inumiya, Kim, \& Choi, 2005). The similar results in the studies on positive illusions cannot be explained with Markus and Kitayama's theory (1991a). In fact, there are a number of studies that do not support the traditional assumptions on cultural differences. 


\subsection{The Evidences that Do Not Support Traditional Cultural Differences}

According to a meta-analysis of studies that used the independent-interdependent self scales (Levine et al., 2003), the differences in self-construal between Easterners and Westerners were very small or inconsistent. While Westerners seemed to have stronger sense of independent self than Easterners, Easterners did not appear to possess strong sense of interdependent self any more than Westerners.

Moreover, there were also some evidences that go against positive illusions, which refer to people's propensity to positively distort certain parts of reality in order to protect or enhance self-esteem (Taylor \& Brown, 1988). While positive illusions have been consistently reported in Western countries, many studies showed such tendency to be very weak or non-existent in Eastern countries in general (Heine \& Hamamura, 2007; Heine et al., 2001; Heine \& Renshaw, 2002; Heine, Takata, \& Lehman, 2000; Markus \& Kitayama, 1991a).

However, some studies have reported that people in certain countries within collectivistic culture have strong positive illusions (Inumiya, Choi, Yoon, Seo, \& Han, 1999; Jung \& Han, 2005; Cho, 2002; Cho \& Myung, 2001). Japanese students showed weak positive illusions on interdependent traits, which are considered as important values for a collectivistic culture, and they also did not have positive illusions on the traits of an individualistic culture (Markus \& Kitayama, 1991b; Heine \& Lehman, 1997; Ito, 1999; Toyama \& Sakurai, 2001). On the other hand, Korean students reported self-enhancing perceptions and strong false uniqueness bias on both independent and interdependent traits as much as the student of the U.S. or Canada (Jung \& Han, 2005; Cho, 2002; Cho \& Myung, 2001). Moreover, Korean students reported stronger feelings of control over negative events than Japanese students, which was as high as Canadian students (Inumiya et al., 1999; Heine \& Lehman, 1995).

An individual's cognitive and motivational processes of such self evaluation (i.e. self-esteem and positive illusions) could be different depending on his/her self-concept (Heine \& Lehman, 1997; Markus \& Kitayama, 1991a, 1991b). Yet, it is hard to explain the disparity between the Koreans and Japanese, the groups that have been believed to belong to the same collectivistic culture. One possible reason why these results do not support Markus and Kitayama's assumptions may be the theoretical simplicity of this dichotomous theory.

The undeniable differences between countries that are generally considered to be in the same culture cannot be explained with the independent-interdependent self theory (Choi, 1993). Thus, other possible explanations need to be considered in order to achieve clearer understanding of culture and human behavior.

\section{An Alternative Explanation}

Individual independence is accepted as representative feature of Western culture but the meaning and concept of interdependence may vary depending on the context in one culture to another. Westerners' interdependent self is constructed from their private and personal relationships, rather than their relationship to the group they belong to (Cross, Bacon, \& Morris, 2000). Indeed, the relation between the self and the group is highly important in the Eastern collectivistic culture. When compared Korean and Japanese individuals, the people of both nations had interdependent self and their self-construal was related to representations of social relationships. However, there were important contrasts in attitudes toward social relationships. Moreover, Korean people had higher level of positive illusion than Japanese (Inumiya \& Kim, 2006).

As the explanation for this difference, Inumiya and Kim (2006) suggested new kinds of self-construal: subjective self and objective self. According to this them, Koreans evaluated themselves very positively because they had a strong subjective self that made them function as a central subject in social relations. In contrast, Japanese individuals evaluated themselves not very positively because they had an objective self that made them act as peripheral objects that merely accepted social influences.

The idea that subjective self is the internalized cultural self-construal of Korean people and objective self is that of Japanese people was based on the fact that the two cultures show interesting distinctiveness in speech/behavior, ethnic sentiment, and self-evaluation (Inumiya, 2003; Inumiya \& Kim, 2006). In respect to language and speech, Korean and Japanese show similarity in word order and vocabulary. However, passive, causative passive, and honorific tenses were frequently present in Japanese, but non-existent or scarcely used in Korean (Oh, 1992; Cheon, 1992). Being the agentic, subjective self is the primary focus of Korean people whereas being the objective self is the main focus for Japanese people. This is why certain linguistic features described above have developed in each culture. As the result, distinctive cultural self-construal has been maintained through the everyday use of such exnressions. Furthermore. the indigenous nsvchological concent exists to renresents distinctive ethnic sentiment in interpersonal relationships. Koreans regard highly of Cheong (정;情) (Lee, 1977; Choi, 2000; Han, 2002), whereas Japanese emphasize Amae (甘え) (Doi, 1971). The former is the emotions that subjective self feels and actively 
"gives" to the object, and the latter is the emotional dependency that is similar to a child's dependency to the mother. Both Korean Choeng and Japanese Amae are originated from the parent-child relationship with strong attachment, empathy, and intimacy, in which the self and others are rarely undifferentiated (Doi, 1971; Choi, 2000). Nonetheless, in Korea the self-construal is conceptualized based on Cheong of the giving self (parent) and in Japan it is based on Amae of the receiving and dependent self (child) (Inumiya, 2003). As with self-evaluation, the degree of self-reflection is varied in the subjective self of Korean people and the objective self of Japanese people. Korean's overall evaluation of the self is relatively more positive than that of Japanese. Korean undergraduate students showed significantly higher self-esteem (Cho et al., 2005), stronger false uniqueness perception (Jeong \& Han, 2005; Cho, 2002; Cho \& Myung, 2001), higher sense of control, and unrealistic optimism (Inumiya et al., 1999).

\subsection{The Alternative Self-Construal Theory: Subjective Self, Objective Self, and Autonomous Self}

Based on the assumptions proposed by Inumiya and Kim (2006), Inumiya, Han, Lee, Lee, and Kim (2007) proposed a self-construal theory that consists of three types: subjective self, objective self and autonomous self. This theory assumes that individuals' self-construal has two different directions in social context. A person would perceive him/herself as an individual separated from social context, or as an inseparable being connected to social context. The former is identical to Markus and Kitayama (1991a)'s independent self. In subjective-objective-autonomous self theory, such kind of self-construal is autonomous self with more emphasis on its role in social context (Inumiya et al., 2007).

Meanwhile, in the latter case there are two types of self-construal, depending on one's regard of his/her influence on social relationship. In other words, an individual would consider him/herself as a central person who has a leading power in the social context, or as a peripheral role who should accept the social influences from others. Inumiya and Kim (2006) had named the former as subjective self, and the latter as objective self. In short, the concepts of these, subjective-objective-autonomous self are derived from the perspective of social context and an individuals' influence in it. Therefore, the proportions of each self-construct would be determined depending on the relationship between individual and society (plus social values). The basic characteristics of these types are summarized in Table 1.

Table 1. Characteristics of Subjective Self, Objective Self, and Autonomous Self

\begin{tabular}{|c|c|c|c|}
\hline & Subjective self & Objective self & Autonomous self \\
\hline Definition & $\begin{array}{l}\text { the central figure who } \\
\text { influences others }\end{array}$ & $\begin{array}{l}\text { the marginal figure who } \\
\text { accepts influence from } \\
\text { others }\end{array}$ & $\begin{array}{l}\text { The autonomous figure } \\
\text { who is independent from } \\
\text { social context }\end{array}$ \\
\hline $\begin{array}{l}\text { Goal } \\
\text { orientation }\end{array}$ & $\begin{array}{l}\text { abide by own } \\
\text { orientation }\end{array}$ & abide by other's orientation & abide by own orientation \\
\hline $\begin{array}{l}\text { Motivation for } \\
\text { relationship }\end{array}$ & $\begin{array}{l}\text { needs for teaching, } \\
\text { managing, guiding, } \\
\text { leading, and governing }\end{array}$ & $\begin{array}{l}\text { needs for learning, } \\
\text { following, assisting, and } \\
\text { depending }\end{array}$ & $\begin{array}{l}\text { needs for self-enrichment } \\
\text { or self-sufficiency }\end{array}$ \\
\hline $\begin{array}{l}\text { Criteria for } \\
\text { self-perception }\end{array}$ & $\begin{array}{l}\text { focusing on internal } \\
\text { criteria: wishes, ideals, } \\
\text { visions }\end{array}$ & $\begin{array}{l}\text { focusing on external criteria: } \\
\text { norms, duties, other's } \\
\text { expectations }\end{array}$ & $\begin{array}{l}\text { focusing on internal } \\
\text { criteria: wishes, ideals, } \\
\text { visions }\end{array}$ \\
\hline $\begin{array}{l}\text { Tendency } \\
\text { toward } \\
\text { self-evaluation }\end{array}$ & $\begin{array}{l}\text { high regard for own } \\
\text { values, abilities, } \\
\text { competences, and } \\
\text { potentiality (low } \\
\text { evaluation on other's) }\end{array}$ & $\begin{array}{l}\text { high regard for other's } \\
\text { values, abilities, } \\
\text { competences, and } \\
\text { potentiality (low evaluation } \\
\text { on one's own) }\end{array}$ & $\begin{array}{l}\text { high regard for own } \\
\text { values, abilities, } \\
\text { competences, and } \\
\text { potentiality (low } \\
\text { evaluation on other's) }\end{array}$ \\
\hline $\begin{array}{l}\text { Dimensions for } \\
\text { self-control }\end{array}$ & $\begin{array}{l}\text { centrifugal, } \\
\text { self-divergent, control } \\
\text { toward the external }\end{array}$ & $\begin{array}{l}\text { centripetal, self-suppressive, } \\
\text { control toward the internal }\end{array}$ & $\begin{array}{l}\text { centrifugal, } \\
\text { self-divergent, control } \\
\text { toward the external }\end{array}$ \\
\hline
\end{tabular}

Autonomous self shares some characteristics with subjective self. Although the characteristics of subjective self were assumed as basic traits of independent self so far, our theory asserts that subjective self should be understood from the perspective of social context. Likewise, autonomous self should be viewed in the same perspective, which is a 
self-construal that is free from social context, even if it is sharing some basic characteristics with independent self.

2.2 The SOA Scale

Inumiya and his colleagues (2007) developed a scale to measure the three types of self-construal: subjective self, objective self, and autonomous self (the SOA scale). In the development of the SOA scale, the authors utilized over 80 items including the scales for independent-interdependent self (Takata, Ohmoto, \& Seike, 1996) and self-esteem (Rosenberg, 1965) as well as the Korean version of the Interpersonal Adjective Scale (Chung, 2004). The surveys were conducted twice, first with 227 participants (M: 112, F: 115) and another with 156 participants (M: 95, F: 61) for cross-validation. Through factor analysis (with direct oblimin by maximum likelihood method), 18 items were extracted. The SOA scale items and basic information are demonstrated in Table 2. The items explaining the three types of self-construal yields sufficient statistical values, which validate their applicability for future quantitative studies.

Table 2. Structure Matrix of the Items

\begin{tabular}{|c|c|c|c|c|}
\hline \multirow{2}{*}{ Items of SOA scale } & \multirow{2}{*}{$M(S D)$} & \multicolumn{2}{|c|}{ Factor1Factor2 } & \multirow{2}{*}{$\begin{array}{c}\text { Factor3 } \\
\mathrm{O}\end{array}$} \\
\hline & & $\mathrm{S}$ & A & \\
\hline It is important that I possess leading control over all situation & $4.56(1.37)$ & .72 & & -.30 \\
\hline I can make others comply with my intentions & $4.51(1.17)$ & .61 & .45 & -.48 \\
\hline I try to be self-assertive and competent & $4.41(1.36)$ & .59 & .46 & \\
\hline I wish to have the power to lead others & $5.39(1.35)$ & .56 & & \\
\hline I have natural talent in influencing others & $3.96(1.24)$ & .53 & .39 & -.33 \\
\hline I often feel the need to be 'the person in the center of power' & $5.13(1.38)$ & .53 & & \\
\hline I like to go around exploring new things. & $4.49(1.64)$ & & .66 & \\
\hline I feel comfortable to make decisions by myself & $4.56(1.51)$ & & .64 & \\
\hline I know how to get along just fine by myself & $4.56(1.47)$ & .33 & .57 & \\
\hline It is important to me to be independent and self-dependent & $4.97(1.41)$ & .48 & .51 & \\
\hline My pleasure and satisfaction are the most important criteria in whatever I do & $5.09(1.37)$ & & .51 & \\
\hline I do things on my own rather than depend on other people or groups & $4.33(1.36)$ & & .45 & \\
\hline I am a follower rather than a leader & $4.05(1.21)$ & -.55 & & .74 \\
\hline I feel uneasy when I stand out from others & $3.53(1.44)$ & & & .61 \\
\hline I would like to be an assistant rather than a leader in a group & $4.19(1.68)$ & -.51 & & .60 \\
\hline It feels easier when someone tells me what to do rather than I tell them & $3.74(1.67)$ & & & .60 \\
\hline In a disagreement of opinion, I mostly follow other's decision & $3.89(1.18)$ & & & .53 \\
\hline I mostly follow my friends' decisions even though they are different from mine & $4.19(1.31)$ & & & .49 \\
\hline Eigen value & & 4.58 & 1.41 & .79 \\
\hline Variance rate & & $25.5 \%$ & $7.9 \%$ & $4.4 \%$ \\
\hline Cronbach's $\alpha$ & & .77 & .74 & .77 \\
\hline Factor mean & & 4.66 & 4.67 & 3.93 \\
\hline (SD) & & $(.90)$ & $(.96)$ & $(1.00)$ \\
\hline
\end{tabular}

Note. Coefficients under . 30 were omitted.

In order to further understand the characteristics of the SOA scale, correlation analyses with other scales were conducted (see Table 3). First, the relations between the factors of the SOA scale and self-esteem were analyzed. Subjective self was assumed to have strong tendency to influence others, and such inclination was assumed to be 
related to positive self-image. Indeed, a positive correlation between subjective self and self-esteem was found $(r$ $=.39, p<.001)$. It was the opposite with objective self $(r=-.44, p<.001)$ because people with stronger objective self tends to regard highly of other people's values. Furthermore, because the autonomous aspects of the self would pursue self-satisfaction, self-sufficiency, and freedom, a positive correlation was found between autonomous self and self-esteem $(r=.32, p<.001)$. Then, the relations between the three types of self-construal in the SOA scale and the Korean version of the Interpersonal Adjective Scale (the IAS) was examined. The IAS-R was devised to measure types of the interpersonal styles based on Kiesler's (1996) interpersonal circumplex theory. According to the theory, there are eight types of attributes in interpersonal relationship derived from two theoretical dimensions (dominance-obedience and friendship-indifference). The resulting types are: dominance (PA), sociability (NO), friendship (LM), naivety (JK), obedience (HI), isolation (FG), indifference (DE), and utility (BC).

It was necessary to compare these interpersonal styles to the three types of self-construal in the SOA scale because both scales are based on the directions of social influence in social context. Among these types, utility (BC), sociability (NO), and dominance (PA) were expected to be in accordance with the attributes of subjective self, whereas naivety (JK), isolation (FG), and obedience (HI) were expected to be in accordance with objective self. Likewise, subjective self showed positive correlations with utility $(r=.21, p<.01)$, dominance $(r=.61, p<.001)$, and sociability $(r=.36, p<.001)$. On the other hand, subjective self showed negative correlations with naivety $(r=$ $-.28, p<.001)$, obedience $(r=-.41, p<.001)$, and isolation $(r=-.27, p<.01)$. These results seem to support the validity of subjective self scale, especially in its relationship with dominance. Secondly, in the relations between objective self and the types of interpersonal patterns, objective self showed positive correlations with naivety $(r=.45$, $p<.001)$, obedience $(r=.61, p<.001)$, and isolation $(r=.46, p<.001)$, whereas it showed negative correlations with utility $(r=-.21, p<.001)$, dominance $(r=-.68, p<.001)$, and sociability $(r=-.46, p<.001)$. These correlations, especially with obedience, also can be the important evidence for the validity of the objective self scale.

Examining the relation between autonomous self and types of interpersonal styles can bring a clearer understanding of the attributes of autonomous self. Autonomous self was partly sharing similar correlations with subjective self, showing positive correlations with utility $(r=.40, p<.001)$ and with dominance $(r=.37, p<.001)$, and negative correlations with naivety $(r=-.18, p<.05)$ and with obedience $(r=-.25, p<.01)$. However, the relationships with dominance $(r=.37)$ and with obedience $(r=-.25)$ were weaker, compared to subjective self (see above). Moreover, autonomous self did not show significant correlations with sociability or friendship, whereas subjective self showed positive correlations with sociability $(r=.24, p<.01)$ and with friendship $(r=.36, p<.001)$. These results support the assumption that there is a theoretical discrimination between subjective self and autonomous self, even if they appear to be alike. In other words, subjective self should be considered in the social context, in which social influences are in effect, whereas autonomous self is assumed to be functioning independently from social context.

Table 3. Correlations of SOA and Other Scales

\begin{tabular}{cccccccccc}
\hline & Self esteem $^{\mathrm{a}}$ & $\mathrm{LM}^{\mathrm{b}}$ & $\mathrm{JK}^{\mathrm{b}}$ & $\mathrm{HI}^{\mathrm{b}}$ & $\mathrm{FG}^{\mathrm{b}}$ & $\mathrm{DE}^{\mathrm{b}}$ & $\mathrm{BC}^{\mathrm{b}}$ & $\mathrm{PA}^{\mathrm{b}}$ & $\mathrm{NO}^{\mathrm{b}}$ \\
\hline Subjective self & $.39^{* * *}$ & $.24^{* *}$ & $-.28^{* * *}$ & $-.41^{* * *}$ & $-.27^{* *}$ & -.07 & $.21^{* *}$ & $.61^{* * *}$ & $.36^{* * *}$ \\
Objective self & $-.44^{* * *}$ & -.11 & $.45^{* * *}$ & $.63^{* * *}$ & $.46^{* * *}$ & .10 & $-.21^{* *}$ & $-.68^{* * *}$ & $-.46^{* * *}$ \\
Autonomous self & $.32^{* * *}$ & -.10 & $-.18^{*}$ & $-.25^{* *}$ & -.03 & .08 & $.40^{* * *}$ & $.37^{* * *}$ & -.03 \\
${ }^{*} p<.05,{ }^{* *} p<.01,{ }^{* * *} p<.001 .{ }^{\mathrm{a}} N=227,{ }^{\mathrm{b}} N=156$ & & & &
\end{tabular}

\subsection{Holistic Thinking, Social Comparison and Regulatory Focus}

In order to apprehend the concept of subjective-objective-autonomous self, the correlations with some variables that were assumed to be affected by the three types of self-construal, independent-interdependent self, and cultural self were examined: holistic thinking, regulatory focus, and social comparison.

The difference in cognition between Eastern and Western is well known as holistic and analytic thinking (Nisbett, et al., 2001; Norenzayan \& Nisbett, 2000). Developed mainly in the Eastern cultures, holistic thinking refers to the cognitive style based on the belief that "every element in the world is somehow connected so it is difficult to understand certain events or object apart from the whole" (Choi, Nisbett, \& Norenzayan, 1999; Nisbett et al., 2001). Prevelent in Western cultures, analytic thinking refers to the cognitive style believing that "the world consists of independent elements" (Choi et al., 1999; Nisbett et al., 2001). 
Indeed, Easterners and Westerners show different cognitive processes. For instance, in cognitive tasks, Americans showed characteristics of being object-dependent, whereas East Asians showed a strong tendency to be field-dependent (Masuda \& Nisbett, 2001; Morris \& Peng, 1994). In terms of categorization, Westerners categorized based on the taxonomical criteria while Easterners categorized in terms of the relations among the elements (Norenzayan, Smith, Kim, \& Nisbett, 2002). For reasoning, Westerners judged true or false based on the formal logic, whereas Easterners preferred dialectics in neutral stance and with tolerant attitude toward the logical contradictions because they believed even the contradicting propositions may be connected together (Peng \& Nisbett, 1999). In terms of prediction for changes, Westerners predicted the linear change with consistent directions of the past trend. On the contrary, Easterners predicted the cyclic change that involved regression toward the mean due to their beliefs on various factors in effect not just the past trends (Ji, Nisbett, \& Su, 2001).

Comparing oneself with others is deeply related with the matter of how one views oneself. This self-awareness is in large part regulated by culture. In Western independent culture people recognize a person as independent beings from the influence of context, and people in Eastern collectivistic culture tend to define a person in specific contexts in life. Markus and Kitayama (1991a) conceptualized these types of self-construal in individualistic and collectivistic cultures as independent self and interdependent self. Independent self is defined as a single and stable self, separated from social contexts. A person with this characteristic is sensitive to her/his internal qualities such as ability, thinking, and feelings, emphasizes self-expression, and prefers direct communication. On the other hand, interdependent self holds flexible and variable characteristics depending on the social contexts, is sensitive to the external qualities such as social status and roles, pursues harmony within the group rather than personal uniqueness, and prefers indirect communication (Markus \& Kitayama, 1991a). The self-view described here may result in the different motivations in the context of social comparisons.

The collectivistic cultural attributes are positively correlated with the tendency for social comparison (Chung \& Mallery, 1999). In White and Lehman's work (2005), Asian Canadians (collectivistic culture) showed social comparison much more than European Canadians, and this result was related to promotion focus in Canadians. Promotion focus is the motivation to improve oneself in terms of accomplishments and is mainly prominent in collectivistic culture. When the task endurance was examined after the success or failure of a task, Japanese in collectivistic culture kept on tasks when failed rather than succeeded, whereas North American was the opposite, where they kept trying when succeeded (Heine et al., 2001). The researchers suggested that such difference was due to the cultural self-views in Japan and North America. Because North Americans view themselves as independent, unique and relatively unchanging beings, the motivation to perceive themselves as positive and enhance themselves is greater. On the contrary, East Asians such as Japanese view themselves as changeable beings in various relationships and the motivation to improve oneself in order to live up to the group goals or other people's standards is greater.

The correlation analysis (Table 4) showed that independent self had positive correlations with subjective self $(r$ $=.467, p<.001)$ and with autonomous self $(r=661, p<.001)$, but had a negative correlation with objective self $(r=$ $-.115, p<.001)$. Interdependent self had positive correlations with subjective self $(r=.231, p<.001)$, with objective self $(r=.424, p<.001)$, and with autonomous self $(r=.270, p<.001)$.

Holistic thinking (AHS scores) showed positive correlations with subjective self ( $r=.147, p<.001$ ), with objective self $(r=.076, p<001)$, and with autonomous self $(r=.318, p<.001)$. Holistic thinking also had positive correlations with independent self $(r=.289, p<.001)$ and with interdependent self $(\mathrm{r}=.339, p<.001)$, which was in agreement with the hypothesis that holistic thinking would be more prominent in collectivistic (interdependent) culture. However, each factors in self-concepts showed different patterns of correlations in regard to subjective-objective-autonomous self theory. With the tendency to accept others' influences, autonomous self was expected to show the highest correlation with holistic thinking, instead it showed the weakest correlation. It was autonomous self, most unrestrained self from social context, that showed the strongest correlations with holistic thinking.

The correlations between promotion focus and independent-interdependent self $(r=.451, p<.001 ; r=.260, p<.001$; respectively) were in accordance with the prediction that stronger independent tendency would be related to higher promotion focus. However, it showed different patterns of correlations with subjective-objective-autonomous self. More specifically, the correlations with objective self $(r=-.112, p<.001)$ and autonomous self $(r=.423, p<.001)$ were similar to the expected results influenced by cultural tendency, whereas the correlation with subjective self was rather strong $(r=440, p<.001)$. Although the study was conducted in interdependent and collectivistic culture, promotion focus had positive correlations with independent self, autonomous self, and subjective self but negative correlation with objective self. 
The correlations between prevention focus and independent-interdependent self $(r=.190, p<.001 ; r=.433, p<.001$; respectively) were in agreement with the prediction that prevention focus would be higher with dominant interdependent self. Again, this was not the case with subjective-objective-autonomous self. Objective self showed the lowest correlation $(r=.184, p<.001)$, and subjective self and autonomous self had similar degree of correlations $(r=.237, p<.001 ; r=.247, p<.001$, respectively).

The correlations between social comparison and independent-interdependent self $(r=.099, p<.001 ; r=.424, p<.001$, respectively) were in accordance with the expected results, which was the inclination to interdependent self would be related to higher social comparison. Unlike the prediction, the correlations with subjective-objective-autonomous self were all positive, with the lowest objective self $(r=.099, p<.001)$, the highest with subjective self $(r=.286, p<.001)$, and somewhat moderate with autonomous self $(r=.167, p<.001)$. These results suggest that the interdependent individuals in the same collectivistic culture would show variations possibly due to the influence of sub-cultures.

Table 4. Correlations of Self-Construal, AHS, Regulatory Focus, and social Comparison

\begin{tabular}{lccccccccc}
\hline & 1 & 2 & 3 & 4 & 5 & 6 & 7 & 8 & 9 \\
\hline 1.Subjective Self & 1.000 & & & & & & & & \\
2.Objective Self & $-.230^{* * *}$ & 1.000 & & & & & & & \\
3.Autonomous Self & $.469^{* * *}$ & $-.049^{*}$ & 1.000 & & & & & & \\
4.Independent Self & $.467^{* * *}$ & $-.115^{* * *}$ & $.661^{* * *}$ & 1.000 & & & & & \\
5.Interdependent Self & $.231^{* * *}$ & $.424^{* * *}$ & $.270^{* * *}$ & $.276^{* * *}$ & 1.000 & & & & \\
6.AHS & $.147^{* * *}$ & $.076^{* * *}$ & $.318^{* * *}$ & $.289^{* * *}$ & $.339^{* * *}$ & 1.000 & & & \\
7.Promotion Focus & $.440^{* * *}$ & $-.112^{* * *}$ & $.423^{* * *}$ & $.451^{* * *}$ & $.260^{* * *}$ & $.467^{* * *}$ & 1.000 & & \\
8.Prevention Focus & $.237^{* * *}$ & $.184^{* * *}$ & $.247^{* * *}$ & $.190^{* * *}$ & $.433^{* * *}$ & $.255^{* * *}$ & $.498^{* * *}$ & 1.000 & \\
9.Social Comparison & $.286^{* * *}$ & $.099^{* * *}$ & $.167^{* * *}$ & $.099^{* * *}$ & $.424^{* * *}$ & $.223^{* * *}$ & $.362^{* * *}$ & $.491^{* * *}$ & 1.000 \\
\hline
\end{tabular}

\section{Cross-Validation in Other Collectivist Countries}

The development and validation of the scale for subjective-objective-autonomous self necessitated content validation of the SOA scale in various countries within the same collectivist culture. Han, Inumiya, Kim, and Zhang (2009) conducted a comparative study with Korean $(N=201$, M: 88, F: 110), Japanese $(N=133$, M: 56, F: 76), and Chinese $(N=128, \mathrm{M}: 45, \mathrm{~F}: 79)$ college students for such purpose. They investigated the levels and the proportions of the three types of self-construal (subjective self, objective self, and autonomous self), and compared them to self-related concepts such as self-esteem and positive illusions within each country and among the three countries.

\subsection{The Differences in Self-Construal Types}

One-way ANOVA showed the differences in self-construal types among the people of the three countries (see Table $5)$. The differences among the countries were found in all three: subjective self $(F=51.419, p<.001)$, objective self $(F=59.344, p<.001)$, and autonomous self $(F=10.396, p<.001)$. In the levels of subjective self, there was no significant differences between Korean $(M=4.81, S D=.89)$ and Chinese $(M=4.63, S D=.94)$, while the level of Japanese subjective self $(M=3.82, S D=1.00)$ was significantly lower than the two other countries. In the case of objective self, Japanese showed the highest level $(M=4.30, S D=1.02)$, Korean was in the middle $(M=3.68, S D$ $=.84)$ and Chinese reported the lowest level $(M=3.06, S D=.93)$. All the differences among the countries were statistically significant. Lastly, in terms of autonomous self, the similar results were observed. That is, Japanese autonomous self $(M=4.60, S D=1.00)$ was lower than the other countries (Korean: $M=4.95, S D=.97$; Chinese: $M$ $=5.12, S D=83)$ and the difference between Korean and Chinese was not significant. 
Table 5. The Differences in Self-Construal Types among the Countries

\begin{tabular}{ccccc}
\hline & Korean & Chinese & Japanese & $F$ \\
\hline $\mathrm{N}$ & 201 & 128 & 133 & \\
\hline \multirow{2}{*}{ Subjective self } & $4.81 \mathrm{a}$ & $4.63 \mathrm{a}$ & $3.82 \mathrm{~b}$ & \multirow{2}{*}{$51.419^{* * *}$} \\
& $(.89)$ & $(.94)$ & $(1.00)$ & \\
Objective self & $3.68 \mathrm{a}$ & $3.06 \mathrm{c}$ & $4.30 \mathrm{~b}$ & $559.344^{* * *}$ \\
& $(.84)$ & $(.93)$ & $(1.02)$ & \\
Autonomous self & $4.95 \mathrm{a}$ & $5.12 \mathrm{a}$ & $4.60 \mathrm{~b}$ & \multirow{2}{*}{$10.396^{* * *}$} \\
& $(.97)$ & $(.83)$ & $(1.00)$ & \\
${ }^{* * *} p<.001$, & & & &
\end{tabular}

$\mathrm{a}, \mathrm{b}, \mathrm{c}$ indicate the results of scheffe's post hoc.

Next, the variation of the patterns in self-construal was examined in accordance with the countries. The main assumption of the self-construal theory in the current study is that an individual's overall self-construal consists of three types, that is subjective self, objective self, and autonomous self, and the overall self-construal would be determined by the proportion of the three. Culture may regulate the specific proportion and the way these three types interplay altogether (Inumiya et al, 2007). A cross-tabulation was executed to examine which country has influenced their people to develop specific type of self-construal (see Table 6).

Depending on their nationality, people were significantly different in dominant self-construal, $\left(\chi^{2}=70.058, p<001\right)$. In both Korean and Chinese participants, the people with dominant autonomous self were the largest groups, followed by those with subjective self and objective self, respectively. In the case of the people who have dominant subjective self, Koreans had a larger group of people (35.8\%) than in Chinese (25.8\%), whereas the proportions of autonomous self were the opposite (Korean: 56.7\%; Chinese: 70.3\%). Although the Japanese people who have dominant autonomous self (50.4\%) were the largest group, the proportion was smaller than those of Korean and Chinese participants. On the other hand, the proportion of the Japanese who have dominant objective self (33.8\%) was the largest among the three countries (Korean: $7.5 \%$; Chinese: $3.9 \%$ ).

Table 6. Crosstab between the Self-Construal Types and Nationality

\begin{tabular}{ccccc}
\hline & Korean (\%) & Chinese (\%) & Japanese (\%) & $\chi^{2}$ \\
\hline Subjective self & $72(35.8)$ & $33(25.8)$ & $21(15.8)$ & \\
Objective self & $15(7.5)$ & $5(3.9)$ & $45(33.8)$ & $70.058^{* * *}$ \\
Autonomous self & $114(56.7)$ & $90(70.3)$ & $67(50.4)$ & \\
$\quad$ total & $201(100)$ & $128(100)$ & $133(100)$ & \\
${ }^{* * *} p<.001$ & & & &
\end{tabular}

The people of the three East Asian nations, Korea, Japan, and China showed dominant subjective self, objective self, and autonomous self, respectively. According to previous results, Korean subjective self (dominant) showed the highest degree of unrealistic optimism and higher self-esteem than Japanese objective self (dominant). No statistical difference was observed with Chinese autonomous self (dominant). Japanese objective self showed the lowest levels of self-esteem and unrealistic optimism among the three countries. Chinese autonomous self indicated higher self-esteem than Japanese objective self and mid-level of unrealistic optimism.

Japanese showed the highest objectivity and Koreans had lower objectivity than Japanese. The fact that Chinese showed the lowest objectivity is noteworthy. It is reasonable to assume that Chinese would have certain level of objectivity especially in terms of social relations because China is regarded as one of the typical collectivist culture. Although it is limited without the direct comparison to individualist culture, the degree of objective self in China is 
fairly low, relatively to that of subjective or autonomous self. On the contrary, objective self in Korea showed a certain degree of dominance, with subjective self being the most predominant.

In general, autonomous self was preeminent in all three nations. Although this may be due to the fact that the participants were young university students with individualistic tendency, it could be the evidence for the substantial need for autonomous self not only in individualist but also collectivist culture.

Utilizing the SOA scale, Han (unpublished, 2012) examined the differences in self-construal among Korea, China, and Japan (Table 7). One-way ANOVA yielded the lowest subjective self in Japanese and no significant difference between Korean and Chinese. Objective self did not show any statistical differences. Autonomous self was the highest in Chinese but Korean and Japanese were not any different.

Table 7. Disparities in Self-Construal among Nations

\begin{tabular}{ccccc}
\hline & Korean & Chinese & Japanese & $F$ \\
\hline $\mathrm{N}$ & 97 & 88 & 88 & \\
\hline \multirow{2}{*}{ Subjective Self } & $4.52^{\mathrm{a}}$ & $4.61^{\mathrm{a}}$ & $4.07^{\mathrm{b}}$ & \multirow{2}{*}{$8.076^{* * *}$} \\
& $(.99)$ & $(.92)$ & $(.98)$ & \\
Objective Self & 4.12 & 3.99 & 4.26 & \multirow{2}{*}{1.859} \\
& $(.85)$ & $(.86)$ & $(1.12)$ & \\
Autonomous Self & $4.79^{\mathrm{a}}$ & $5.18^{\mathrm{b}}$ & $4.52^{\mathrm{a}}$ & \multirow{2}{*}{$13.387^{* * *}$} \\
${ }^{* * *} p<.001$, & $(.83)$ & $(.85)$ & $(.87)$ & \\
\hline
\end{tabular}

$\mathrm{a}, \mathrm{b}$ indicate the results of scheffe's post hoc.

In comparison with previous results (Han et al., 2009), a consistent results emerged in subjective self. Japanese had the highest inclination to objective self but there was no overall difference among the three nations. The proportion for autonomous self was significantly higher in Korean and Chinese than Japanese in 2009 but Chinese alone had the highest ratings in 2015. Even though the patterns of rates were consistent, the difference between Korea and Japan was not statistically significant. Moreover, cross-tabulation analysis showed a significant relations between nationality and self-construal $\left(\chi^{2}=16.556, p<01\right)$.

All three nations had the highest percentage of individuals with dominant autonomous self (Table 8). The rates for dominant subjective self were the highest in Korean (37.9\%), whereas Japanese (25.0\%) and Chinese (23.9\%) showed lower rates. The rates for dominant objective self was the highest in Japanese (35.2\%), whereas those of Korean $(18.9 \%)$ and Chinese $(15.9 \%)$ were relatively lower. The rates for dominant autonomous self were the highest in Chinese (60.2\%), followed by Korean (43.2\%) and Japanese (39.8\%). This was in accordance with the previous results (Han et al., 2009). Taken altogether, all three nations indeed showed different dominant self-construal: subjective self in Korea, objective self in Japan, and autonomous self in China.

Table 8. Individuals with Dominant Subjective-Objective-Autonomous Self

\begin{tabular}{ccccc}
\hline & Korean (\%) & Chinese (\%) & Japanese (\%) & $\chi^{2}$ \\
\hline Subjective Self & $36(37.9)$ & $21(23.9)$ & $22(25.0)$ & \\
Objective Self & $18(18.9)$ & $14(15.9)$ & $31(35.2)$ & \multirow{2}{*}{$16.556^{* *}$} \\
Autonomous Self & $41(43.2)$ & $53(60.2)$ & $35(39.8)$ & \\
$\quad$ Total & $95(100)$ & $88(100)$ & $88(100)$ & \\
${ }^{* *} p<.01$ & & & &
\end{tabular}




\subsection{The Relation between SOA Types and Self-Related Concepts in Collectivist Nations}

Individual's type of dominant self-construal was expected to be related to her/his self-concepts. Han and his colleagues (2009) measured self-esteem (Rosenberg, 1965) and positive illusions (Heine \& Lehman, 1995) of participants in Korea, Japan, and China, and also analyzed the differences and relations were among these variables. A one-way ANOVA was conducted to show the differences in the level of self-related concepts among the countries (Table 9).

The differences among the countries were statistically significant in self-esteem $(F=45.993, p<.001)$ and unrealistic optimism $(F=19.440, p<.001)$. In self-esteem, the difference between Korea and China was not significant, while the levels of self-esteem in Korea and China were higher than that in Japan. In terms of unrealistic optimism, however, Koreans $(M=8.61, S D=12.03)$ reported the highest level of unrealistic optimism, followed by Chinese $(M$ $=5.16, S D=11.17)$ and Japanese $(M=.13, S D=13.11)$. All the differences among the three countries were statistically significant.

Table 9. The Differences of Self-Related Concepts

\begin{tabular}{cccccc}
\hline & Korean & Japanese & Chinese & $\begin{array}{c}\text { M } \\
(S D)\end{array}$ & $F$ \\
\hline$N$ & 201 & 133 & 127 & & \\
Self-esteem & $5.11 \mathrm{a}$ & $4.06 \mathrm{~b}$ & $4.83 \mathrm{a}$ & 4.73 & $45.993^{* * *}$ \\
& $(1.08)$ & $(.98)$ & $(.83)$ & $(1.08)$ & \\
Unrealistic & $8.61 \mathrm{a}$ & $.13 \mathrm{~b}$ & $5.16 \mathrm{c}$ & 5.21 & \multirow{2}{*}{$19.440^{* * *}$} \\
optimism & $(12.03)$ & $(13.11)$ & $(11.17)$ & $(12.61)$ & \\
${ }^{* * *} p<.001$ & & & & &
\end{tabular}

$a, b, c$ indicate the results of scheffe's post hoc.

Note. Unrealistic optimism was measured by the absolute way (Heine \& Lehman, 1995)

Next, different patterns of correlations emerged as well (Table 10). The correlation between subjective self and objective self (negative), subjective self and self-esteem (positive), objective self and autonomous self (n.s.), objective self and self-esteem (negative), autonomous self and unrealistic optimism (n.s.), and self-esteem and unrealistic optimism (positive) showed the same patterns of results, irrespective of nationality. On the other hand, there were different patterns of correlations between subjective self and autonomous self, between objective self and unrealistic optimism, and between autonomous self and self-esteem, depending upon the countries. In other words, the correlations between subjective self and autonomous self were positive in Korea $(r=.347, p<.001)$ and China $(r$ $=.324, p<.001)$, whereas there was no significant correlation in Japan $(r=.061, n . s$. $)$. In addition, the correlations between subjective self and unrealistic optimism were not significant in Korea $(r=.114$, n.s. $)$ and China $(r=.138$, $n . s$.$) , while a relatively clear correlation was found in Japan (r=.338, p<.001)$.

In the correlation between objective self and unrealistic optimism, China $(r=-.243, p<.001)$ and Japan $(r=-.234$, $p<.001)$ showed a significantly negative relationship, whereas there was no significant correlation in Korea $(r=$ $-.031, n . s$. ). Lastly, the correlation between autonomous self and self-esteem were significantly positive in Korea $(r$ $=.209, p<.01)$ and China $(r=.206, p<.05)$, while it was not significant in Japan $(r=.049, n . s$. $)$. 
Table 10. Correlation between the Self-Construal Types and Self-Related Concepts

\begin{tabular}{|c|c|c|c|c|c|c|}
\hline & & 1 & 2 & 3 & 4 & 5 \\
\hline \multirow{3}{*}{$\begin{array}{c}\text { 1. subjective } \\
\text { self }\end{array}$} & Korean & 1.000 & & & & \\
\hline & Chinese & 1.000 & & & & \\
\hline & Japanese & 1.000 & & & & \\
\hline \multirow{3}{*}{$\begin{array}{l}\text { 2. objective } \\
\text { self }\end{array}$} & Korean & $-.325^{* * *}$ & 1.000 & & & \\
\hline & Chinese & $-.413^{* * *}$ & 1.000 & & & \\
\hline & Japanese & $-.452^{* * *}$ & 1.000 & & & \\
\hline \multirow{3}{*}{$\begin{array}{l}\text { 3. autonomous } \\
\text { self }\end{array}$} & Korean & $.347^{* * *}$ & -.001 & 1.000 & & \\
\hline & Chinese & $.324^{* * *}$ & -.004 & 1.000 & & \\
\hline & Japanese & .061 & -.028 & 1.000 & & \\
\hline \multirow{3}{*}{ 4. self-esteem } & Korean & $.295^{* * *}$ & $-.295^{* * *}$ & $.209^{* *}$ & 1.000 & \\
\hline & Chinese & $.289^{* * *}$ & $-.348^{* * *}$ & $.206^{*}$ & 1.000 & \\
\hline & Japanese & $.361^{* * *}$ & $-.457^{* * *}$ & .049 & 1.000 & \\
\hline \multirow{3}{*}{$\begin{array}{l}\text { 5. unrealistic } \\
\text { optimism }\end{array}$} & Korean & .114 & -.031 & .096 & $.228^{* * *}$ & 1.000 \\
\hline & Chinese & .138 & $-.243^{* * *}$ & .112 & $.266^{* *}$ & 1.000 \\
\hline & Japanese & $.338^{* * *}$ & $-.234^{* *}$ & .009 & $.434^{* * *}$ & 1.000 \\
\hline
\end{tabular}

\section{Discussion}

Due to the various yet distinctive characteristics within the same culture and the simplicity of the dichotomous categorization, an alternative explanation was needed in order to fully comprehend the relation between culture and self. The current study introduced three types of self-construal and showed the application to the cross-cultural field, especially to the collectivist culture. More specifically, the current results showed that there were indeed different dominant types of self-construals within the same collectivist culture.

The current results also showed the valid explanation for different levels of optimisms within the collectivist culture. In culture like Korea where subjective self is dominant, identity maintenance is closely linked to people's tendency to seek and affirm their special qualities in order to obtain reassurance from the self as well as others. This is mainly due to the characteristic of the self as the central being of exerting social influence. Thus, people with subjective self may be motivated to achieve social superiority through the discovery of such desirable qualities and the realization of those qualities in both personal and social levels.

If that is indeed the case, people in the culture of subjective self (i.e., Korea) may have developed various psychological mechanisms to maintain and increase self-esteem. Particularly, the focus of selective attention would be on one's desirable qualities. In other words, one would retain a habit of frequently contemplating over such information. The reason why Koreans have positive illusions for the features the self, sense of control, and the future is because they perceive themselves not as independent beings (Kitayama, 1998) but as the agentic and subjective being exerting social power.

Such selective focus may result in self-serving bias in attributional inference. When one achieves the anticipated result (e.g., success), one accepts it as is and presumes one's desirable internal qualities (e.g., high level of ability) as the explanation. On the other hand, when the undesired result (e.g., failure) occurs, one tries to preserve one's desirable internal qualities (e.g., high level of ability) that is contradicting to the outcome, and speculates other external factors in order to resolve this contradiction. The self-serving attribution in success leads to validation of subjective self, and self-protecting attribution prevents the damage to subjective self. The memory of a successful experience that confirms subjective self would be more retainable than the memory of failure, and such self-serving interpretation and selective memory would consequently enable positive perception on self-features and sense of control. This would in turn lead to optimistic view for the future (Inumiya \& Kim, 2006).

On the contrary, for the people in culture of objective self, identity maintenance is closely linked to finding the 
important official relationships. Thus, they are motivated to include the self as the object in the social relations. For the people with objective self, the main interest is not maintaining or increasing the evaluation of internal qualities to achieve social superiority, therefore such goals would seldom motivate them. In order to include oneself in social relations, one must grasp the expectations, standards, and values of group members. Also one must recognize one's flaws and shortcomings by comparing them to one's aught self, which is comprised of the internalized external standards. By doing so, one is finally able to include oneself to adjust and place oneself in the relationships.

If this is indeed the case, the people of culture with objective self (i.e., Japan) would selectively attend to their undesirable qualities. By focusing their attention to such information, they would be accustomed to the psychological habit of contemplation on those qualities. Japanese seldom show positive illusions and instead show self-critical cognitions because they perceive themselves not as interdependent beings (Kitayama, 1998) but as the objects who get influenced in social relations. Such selective attention results in self-critical bias in terms of attributional inference. When the expected yet undesired results (e.g., failure) occur, one accepts it as is, and autonomously presumes the consistently undesirable internal qualities (e.g., low level of ability). However, when the unexpected yet beneficial results (e.g., success) occur, the contradicting but desirable internal qualities (e.g., high level of ability) are presumed, and other various external factors are conjectured in order to resolve the contradiction. Self-modesty attribution in success leads to validation of objective self, and self-critical attribution leads to advancement or improvement of objective self. The memory of failures that confirms subjective self would be more retainable than that of success, and such self-critical interpretation and selective memory would result in negative perception of self-features and the sense of control. This would in turn lead to pessimistic view for the future (Inumiya \& Kim, 2006).

China was in between Korea and Japan, the underlying reason of which is unclear. It is possibly due to the unqualified subjects as representatives of Chinese nation. Although further research is necessary, it still holds the significant meanings.

There were clear differences in self-construal among the countries that have been believed to have the same self-construal (i.e., interdependent self). And the results were supported with the reliability and validity of the scale. Considering the evidences showed in this article, the new self-construal theory can supplement Markus and Kitayama's theory and suggests a new direction to the cross-cultural studies. For example, it may be utilized to reveal cultural diversity of the same culture (i.e., individualistic or collectivistic culture).

The current theory shares the assumption of Triandis (1988) that there are two types of culture, individualistic culture and collectivistic culture. It also agrees with Markus and Kitayama's (1991a) assertion that self-construal may vary depending on the type of culture. However, it should be noted that there can be variations of the cultural type and self-construal within the same category of culture. As the only theory for culture and self, the theory of independent-interdependent self (Markus \& Kitayama, 1991a) has played an important role in explaining cultural differences between Western and Eastern countries. However, there exist over 200 countries that have distinct lifestyles and acts of meaning (i.e., cultures) that is beyond the dichotomous categorization.

Questions have been also raised about the validity and reliability of the basic assumptions surrounding Triandis's (1988) cultural distinction, individualism and collectivism (Triandis, McCusker, \& Hui, 1990; Matsumoto, Kudoh, \& Takeuchi, 1996; Takano \& Osaka, 1999; Oyserman, Coon \& Kemmelmeier, 2002). To provide better explanations, Triandis and Gelfand (1998) added two factors, horizontal vs. vertical, which reflect the subordination to hierarchical order of a certain culture. In other words, researchers can approach four types of culture: horizontal individualistic, vertical individualistic, horizontal collectivistic, and vertical collectivistic. Even though this new framework seems to provide a better explanation for the cultural diversity, there still exists the problem of dichotomy. Matsumoto (1999) claimed that Markus and Kitayama's (1991a) self-construal theory has only shown the relationship between independent variable (i.e., USA and Japan) and dependent variable (i.e. independent self and interdependent self). Therefore, it cannot be the evidence for the actual difference of self-construal.

There can be another problem when researchers interpret the results of the studies adopting a reformed framework (Triandis \& Gelfand, 1998). Many researchers asserted the reason why it is hard to see the results that support the assumption of distinctive individualism and collectivism would be due to changes of cultures (Ryu, 2009; Park \& Lee, 2004; Lim, 1994; Han \& Shin, 1999). In other words, people who belong to collectivistic culture may change their cultural attributes once they accept individualistic values through the experience of modernization. Although their assertions deserve an attention, it should be also noted that Korea is not the only country experiencing rapid modernization in recent decades. The same processes are occurring in many countries categorized as collectivistic culture. However, there is not much evidence that they vary in cultural self-construal. It only becomes clearer that 
dichotomous frameworks cannot help us reach a reason.

Researchers could lose a lot of information that may provide valuable knowledge by abiding in the traditional dichotomous framework. For instance, some researchers can ignore the results that do not support the assumptions of their dichotomous framework because those results tend to be interpreted as irregular exceptions (Han, 2003).

The current theory started with the notion that Markus and Kitayama's (1991a) theory has constantly failed to explain the differences between Korean and Japanese, who were all believed to have interdependent self. To complement the weaknesses of this theory, three different types of self-construal are proposed: subjective self, objective self, and autonomous self. It reflects the ways an individual makes connections with others in social contexts. In addition, the current theory assumed that the proportion (dominance) of self-construal types and their interactions may be influenced by culture. Thus, the patterns of self-construal constructed with these types would vary depending on cultures and nations.

While Markus and Kitayama's (1991a) theory can provide restrictive explanations for the difference between individualist and collectivist culture, our SOA theory could explain the cultural differences from the countries that have been thought to belong to the same culture, as we demonstrated in this study. The results of the recent studies utilizing the newly proposed SOA framework showed the actual differences of self-construal among the countries, as well as the psychological characteristics of collectivist cultures that tended to be limited to Japanese culture (Han et al., 2009; Inumiya, 2009).

The evidences revealed in the studies applying the SOA theory confirm that the alternative theory could provide a new perspective to cross-cultural studies. While cross-cultural psychology has been focusing on the dichotomous differences between Western and Eastern culture, there are plenty of evidences supporting the differences within the same culture. It is time to expand our understanding of cultures by paying more attention to the variety of subcultures beyond the individualistic-collectivistic frame. The SOA theory successfully fulfills this purpose. Future studies based on this theory could provide clearer explanations about culture and human behaviors.

The SOA theory needs to be validated in various cultures both theoretically and empirically, not only between the countries that have been considered as collectivistic culture but also between individualistic countries. Especially, the theoretical approaches of independent self should be conducted. Just as reconsideration of the interdependent self-construct has resulted in many critiques, regarding the assumptions of cultural differences in collectivistic cultures, the same efforts on independent self could lead us to better understanding of the individualistic cultures.

\section{References}

Baumeister, R, F., Tice, D. M., \& Hutton, D. G. (1989). Cognitive processes during deliberate self-presentation: How self-presenters alter and misinterpret the behavior of their interaction partners. Journal of Experimental Social Psychology, 25(1), 59-78. http://dx.doi.org/10.1111/j.1467-6494.1989.tb02384.x

Cheon, S. (1992). The difference of language conception between Korean and Japanese, (I) idiom. Kyungsung University Bulletin, 13(1), 121-137.

Cho, G. (2002). Cultural dispositions and false uniqueness effects. Korean Journal of Social and Personality Psychology, 16(1), 91-111.

Cho, G. H., \& Myung, J. W. (2001). Cultural dispositions and types of self-consciousness. Korean Journal of Social and Personality Psychology, 15(2), 111-139.

Cho, S., Inumiya, Y., Kim, J., \& Choi, I. (2005). Effects of independent-interdependent self construal on social anxiety in South Korea and Japan: Mediational effects of self-esteem and public self-consciousness. Korean Journal of Social and Personality Psychology, 19(4), 49-60.

Choi, I., Nisbett, R. E., \& Norenzayan, A. (1999). Causal attribution across cultures: variation and universality. Psychological Bulletin, 125(1), 47-63. http://dx.doi.org/10.1037/0033-2909.125.1.47

Choi, S. (1993). Characteristics of Korean, Korean's shimcheong psychology: A phenomenological understanding of cheong and han. Symposium of Korean Psychological Association, 3-21.

Choi, S. (2000). Korean psychology. Seoul: Chungang University Press.

Chung, N. (2004). Construction of the circumplex scales for Korean version of the interpersonal adjective scales (KIA-40). The Korean Journal of Counseling and Psychotherapy, 16(1), 37-51. 
Chung, T., \& Mallery, P. (1999). Social comparison, individualism-collectivism, and self-esteem in China and the United States. Current Psychology, 18(4), 340-352. http://dx.doi.org/10.1007/s12144-999-1008-0

Cross, S. E., Bacon, P. L., \& Morris, M. L. (2000). The relational-interdependent self-construal and relationships. Journal of Personality and Social Psychology, 78(4), 791-808. http://dx.doi.org/10.1037/0022-3514.78.4.791

Danziger, K. (1997). The varieties of social construction. Theory \& Psychology, 7(3), 399-416. http://dx.doi.org/10.1177/0959354397073006

Devos, G. A. (1973). Socialization for achievement. Berkeley, CA: University of California Press.

Doi, T. (1973). The anatomy of dependence. Tokyo: Kodansha America, Inc. [Japanese]

Han, G., \& Shin, S. (1999). A cultural profile of Korean society: From vertical collectivism to horizontal individualism. Korean Journal of Social and Personality Psychology, 13(2), 293-310. [Korean]

Han, G. (2002). Understanding social psychology. Seoul: Hakjisa.

Han, M., Inumiya, Y., Kim, S., \& Zhang, W. (2009). The application of culture bounded self-construal model: A comparative study between three countries in Northeast Asia. Korean Journal of Psychology: General, 28(1), 49-66. [Korean]

Han, S. (2003). Cross-cultural study of the relationship between self-enhancement bias and psychological adjustment. Korean Journal of Psychological and Social Issues, 9(2), 79-99.

Harré, R., \& Gillett, G. (1994). The discursive mind. Thousand Oaks, CA: Sage Publications.

Heine, S. J., \& Hamamura, T. (2007). In search of East Asian self-enhancement. Personality and Social Psychology Review, 11(1), 4-27. http://dx.doi.org/10.1177/1088868306294587

Heine, S. J., \& Lehman, D. R. (1995). Cultural variation in unrealistic optimism: Does the west feel more invulnerable than the east? Journal of Personality and Social Psychology, 68, 595-607. http://dx.doi.org/10.1037/0022-3514.68.4.595

Heine, S. J., \& Renshaw, K. (2002). Interjudge agreement, self-enhancement, and liking: Cross-cultural divergences. Personality and Social Psychology Bulletin, 28(5), 578-587. http://dx.doi.org/10.1177/0146167202288002

Heine, S. J., \& Lehman, D. R. (1997). The cultural construction of self-enhancement: An examination of group-serving biases. Journal of Personality \& Social Psychology, 72(6), 1268-1283. http://dx.doi.org/10.1037/0022-3514.72.6.1268

Heine, S. J., Kitayama, S., Lehman, D. R., Takata, T., Ide, E., Leung, C., \& Matsumoto, H. (2001). Divergent consequences of success and failure in Japan and North America: An investigation of self-improving motivations and malleable selves. Journal of Personality and Social Psychology, 81, 599-615. http://dx.doi.org/10.1037/0022-3514.81.4.599

Heine, S. J., Takata, T., \& Lehman, D. R. (2000). Beyond self-presentation: Evidence for self-criticism among Japanese. Personality and Social Psychology Bulletin, 26(1), 71-78. http://dx.doi.org/10.1177/0146167200261007

Hsu, F. L. K. (1981). Americans and Chinese: Passage to differences. Honolulu, HI: University Press of Hawaii.

Inumiya, Y. (2003). Personality of Korean and Japanese. Japanese Research, 11, 103-125. [Japanese]

Inumiya, Y. (2009). A comparison of positive Illusions in South Korean and Japanese: Subjective self and objective Self. Journal of Psychology: General, 28(1), 115-146.

Inumiya, Y., Choi, I., Yoon, D., Seo, D., \& Han, S. (1999). The relationship between unrealistic optimism and independent-interdependent construals of self in Korean culture. Korean Journal of Social and Personality Psychology, 13(1), 183-201.

Inumiya, Y., Han, M., Lee, D. I., Lee, J. H., \& Kim, S. H. (2007). Development of a cultural self-construal scale: Subjective, objective, and autonomous selves. Korean Journal of Social Psychology, 21(2), 17-34.

Inumiya, Y., \& Kim, Y. J. (2006). A comparison of positive illusions between South Korean and Japanese: Explanation by subjective self and objective self. Korean Journal of Social Psychology, 20(4), 19-34.

Ito, T. (1999). Self-enhancement tendency in self and other evaluations: An examination of 'better-than-average effect. The Japanese Journal of Psychology, 70(5), 367-374. 
Ji, L. J., Nisbett, R. E., \& Su, Y. (2001). Culture, change, and prediction. Psychological Science, 12(6), 450-456. http://dx.doi.org/10.1111/1467-9280.00384

Jung, W., \& Han, G. (2005). Self-esteem as a moderator of self-enhancing tendency. Korean Journal of Social and Personality Psychology, 19(1), 199-216. [Korean]

Kiesler, D. J. (1996). From communications to interpersonal theory: A personal odyssey. Journal of Personality Assessment, 66(2), 267-282. http://dx.doi.org/10.1207/s15327752jpa6602_6

Kitayama, S. (1998). Self and emotions: Questions for cultural psychology. Tokyo: Kyoritsu Publishing.

Kwan, V. S. Y., Bond, M. H., \& Singelis, T. M. (1997). Pancultural explanations for life satisfaction: Adding relationship harmony to self-esteem. Journal of Personality and Social Psychology, 73, 1038-1051. http://dx.doi.org/10.1037/0022-3514.73.5.1038

Lee, H. (1980). External-internal control. Studies on Lives of Students (Chungbuk University), 5, 41-51. [Korean]

Levine, T. R., Bresnahan, M. J., Park, H. S., Lapinski, M. K., Wittenbaum, G. M., Shearman, S. M., Lee, S. Y., Chung, D., \& Ohashi, R. (2003). Self-construal scales lack validity. Human Communication Research, 29(2), 210-252. http://dx.doi.org/10.1111/j.1468-2958.2003.tb00837.x

Lim, H. (1994). The change of Korean society and values. Seoul: Nanam.

Markus, H., \& Kitayama, S. (1991a). Culture and self: implications for cognition, emotion, and motivation. Psychological Review, 98, 224-253. http://dx.doi.org/10.1037/0033-295X.98.2.224

Markus, H., \& Kitayama, S. (1991b). Cultural variation in the self-concept. In J. Strauss \& G. R. Goethals (Eds.), The self: Interdisciplinary approaches. New York, NY: Springer-Verlag.

Masuda, T., \& Nisbett, R. E. (2001). Attending holistically versus analytically: Comparing the context sensitivity of Japanese and Americans. Journal of Personality and Social Psychology, 81(5), 922-934. http://dx.doi.org/10.1037/0022-3514.81.5.922

Matsumoto, D. (1999). Culture and self: An empirical assessment and interdependent self-construal. Asian Journal of Social Psychology, 2, 289-310. http://dx.doi.org/10.1111/1467-839X.00042

Matsumoto, D., Kudoh, T., \& Takeuchi, S. (1996). Changing patterns of individualism and collectivism in the United States and Japan. Culture Psychology, 2, 77-107. http://dx.doi.org/10.1177/1354067X9621005

Morris, M. W., \& Peng, K. (1994). Culture and cause: American and Chinese attributions for social and physical events. Journal of Personality and Social Psychology, 67(6), 949-971.

Nisbett, R. E., Peng, K., Choi, I., \& Norenzayan, A. (2001). Culture and systems of thought: holistic versus analytic cognition. Psychological Review, 108(2), 291-310. http://dx.doi.org/10.1037/0033-295X.108.2.291

Norenzayan, A., \& Nisbett, R. E. (2000). Culture and causal cognition. Current Directions in Psychological Science, 9(4), 132-135. http://dx.doi.org/10.1111/1467-8721.00077

Norenzayan, A., Smith, E. E., Kim, B. J., \& Nisbett, R. E. (2002). Cultural preferences for formal versus intuitive reasoning. Cognitive Science, 26(5), 653-684.

Oh, S. (1992). The new wind: Korea and Japan=the world of double mirroring. Tokyo: Samwoosa. [Japanese]

Oyserman, D., Coon, H., M., \& Kemmelmeier, M. (2002). Rethinking individualism and collectivism: Evaluation of theoretical assumptions and meta-analyses. Psychological Bulletin, 128, 3-72. http://dx.doi.org/10.1037/0033-2909.128.1.3

Park, H., \& Lee, Y. (2004). A study on the relationship among individualism-collectivism, client's expectations of the counselor's role, and therapeutic factors with group counseling participants. The Korean Journal of Counseling and Psychotherapy, 16(4), 571-596.

Peng, K., \& Nisbett, R. E. (1999). Culture, dialectics, and reasoning about contradiction. American Psychologist, 54(9), 741-754. http://dx.doi.org/10.1037/0003-066X.54.9.741

Rosenberg, M. (1965). Society and the adolescent self-image. Princeton, NJ: Princeton University Press.

Ryu, S. (2009). Attitude toward the employability of people with mental disorders: Comparative study of Korea and U.S.. Korean Journal of Social and Personality, 23(4), 1-25.

Takano, Y., \& Osaka, E. (1999). An unsupported common view: Comparing Japan and the U.S. on 
individualism/collectivism. Asian Journal of Social Psychology, 2, 311-341. http://dx.doi.org/10.1111/1467-839X.00043

Takata, T., Omoto, M., \& Seike, M. (1996). Construction of a revised scale for independent and interdependent construal of self. Memoirs of the Nara University, 24, 157-173.

Taylor, S. E., \& Brown, J. D. (1988). Illusion and well-being: A social psychological perspective on mental health. Psychological Bulletin, 103(2), 193-210. http://dx.doi.org/10.1037/0033-2909.103.2.193

Toyama, M., \& Sakurai, S (2001). Positive illusions in Japanese students. The Japanese Journal of Psychology, 72(4), 329-335.

Triandis, H. C. (1988). Collectivism vs. individualism: A reconceptualization of a basic concept in cross-cultural social psychology. In G. K. Verma and C. Bagley (Eds.), Cross-Cultural Studies of Personality, Attitudes and Cognition (pp.60-95). London: Macmillan.

Triandis, H. C., \& Gelfand, M. J. (1998). Converging measurement of horizontal and vertical individualism and collectivism. Journal of Personality and Social Psychology, 74, 118-128. http://dx.doi.org/10.1037/0022-3514.74.1.118

Triandis, H. C., McCusker, C., \& Hui, C. H. (1990). Multimethod probes of individualism and collectivism. Journal of Personality and Social Psychology, 59, 1006-1020. http://dx.doi.org/10.1037/0022-3514.59.5.1006

White, K., \& Lehman, D. R. (2005). Culture and social comparison seeking: The role of self-motives. Personality and Social Psychology Bulletin, 31(2), 232-242. http://dx.doi.org/10.1177/0146167204271326 